\title{
Regression of asymptomatic intracranial arterial stenosis by aggressive medical management with a lipid-lowering agent
}

\author{
Bo Seok Kim, Jun Seob Lim, Jae Uk Jeong, Jong Hyun Mun, Sung Hyun Kim \\ Kwangju Christian Hospital
}

Objective : The incidence rate of stroke as a result of intracranial arterial stenosis (ICAS) is higher in Asian countries than in the West. We aimed to analyze the regression, lack of change, or progression of asymptomatic ICAS after the administration of rosuvastatin and associated factors.

Methods : The patients who had undergone computed tomography angiography (CTA) at our hospital and had been diagnosed with ICAS with no ischemic event in the stenosed vascular territory were included in the study. They were administered $20 \mathrm{mg}$ of rosuvastatin per day. After a follow-up period of at least 6 months after treatment, the patients were examined using CTA again and the clinical information and imaging results were analyzed.

Results : In total, 48 patients were diagnosed with asymptomatic ICAS. During the final follow-up examination, it was found that the stenotic lesion regressed in 30 patients, whereas it remained unchanged or progressed without any adverse effects in 18 patients. In univariate analysis, the regressed group showed significantly higher differences in the levels of total cholesterol and low-density lipoprotein (LDL) between their initial and final values (both, $p=0.031$ for both). In the multivariate analysis, a significantly higher difference in the levels of LDL between its initial and final measurement was seen in the regressed group $(p=0.035$, odds ratio(OR) 3.9).

Conclusions : Rosuvastatin was found to have better lipid-lowering effects for total cholesterol and particularly LDL in patients whose ICAS had regressed. We concluded that rosuvastatin administration can be recommended for the treatment of patients with asymptomatic ICAS.

Keywords intracranial arterial stenosis, stroke, atherosclerosis, statin

\author{
J Cerebrovasc Endovasc Neurosurg. \\ 2019 September;21(3):144-151 \\ Received : 1 August 2018 \\ Revised : 2 September 2019 \\ Accepted : 18 September 2019 \\ Correspondence to JunSeob Lim \\ Kwangju Christian Hospital \\ Tel : 062-650-5133 \\ Fax : 062-650-5134 \\ E-mail : nsmh1@hanmail.net \\ ORCID : http://orcid.org/0000-0002-9944
}

This is an Open Access article distributed under the terms of the Creative Commons Attribution NonCommercial License (http://creativecommons.org/licenses/by-nc/3.0) which permits unrestricted noncommercial use, distribution, and reproduction in any medium, provided the original work is properly cited.

\section{INTRODUCTION}

Intracranial arterial stenosis (ICAS) is a major cause of ischemic stroke, which may occur even under the best medical management. ${ }^{23)}$ It is estimated that ICAS causes approximately $5-10 \%$ of ischemic strokes in the
United States and 33-67\% of ischemic strokes in Asia. ${ }^{26)}$ Recently, a rapid emergence of atherosclerosis in Asia was reported in relation to coronary artery disease, ${ }^{27)}$ which may additionally be associated with the high prevalence of ICAS-induced stroke.

Several mechanisms have been proposed with re- 
gard to ICAS-related ischemic events: in situ thrombotic occlusion, hypoperfusion, artery-to-artery embolism, and atheromatous-plaque-extension over small arteries. ${ }^{4) 1618)}$ ICAS is usually caused by primary atherosclerosis, although embolism can occasionally lead to severe stenosis. ${ }^{5}$ ) Other sources of ICAS include vascular inflammation, infections of the central nervous system, radiation, arterial dissection, and Moyamoya disease. ${ }^{14)}$

Aggressive medical management for symptomatic ICAS is assumed to be more effective than percutaneous transluminal angioplasty and stenting. $\left.{ }^{6}\right)$ Medical management with the administration of lipid-lowering agents has been recommended by several large studies. ${ }^{6) 8}$

Although there is no general consensus on the treatment of asymptomatic ICAS, aggressive management seems to be required in such cases as well. However, in spite of the exploration of different treatment options, the prognosis of asymptomatic ICAS has not been thoroughly investigated to date. The prognosis of asymptomatic atherosclerotic stenosis of the middle cerebral artery is reported to follow a benign long-term course with a low risk of ipsilateral stroke in medically-treated Caucasian patients. ${ }^{15)}$ However, an Asian study has reported that asymptomatic ICAS by itself was an independent risk factor of stroke. ${ }^{19)}$

Thus far, the association between the regression of ICAS and the administration of lipid-lowering agents has been reported by few studies. However, there have been no studies comparing a regressed ICAS group with a static or progressive group after the administration of rosuvastatin. In this study, we compared patients with regressed ICAS to those with unchanged or progressed ICAS after medical treatment, and investigated the related factors.

\section{MATERIALS AND METHODS}

\section{Study design}

This study was performed based on a review of the patient's medical charts and the study design was approved by the Institutional Review Board (IRB) of KCHIRB-M-2018-101. The requirement of informed consent was waived by the IRB. Before including subjects in the study, asymptomatic ICAS was defined as the absence of ischemic events in the territory supplied by the stenosed artery. Patients who had experienced symptomatic ischemic events including transient ischemic attack (TIA) in the stenosed artery or cerebral infarction in the ipsilateral area, which were proven by imaging analysis, were excluded. Asymptomatic ICAS was detected in patients who had not experienced a stroke, including those who had visited our institution for a regular medical checkup or were complaining of a headache. The diagnosis of asymptomatic ICAS was confirmed with computed tomography angiography (CTA), following which the patients were administered $20 \mathrm{mg}$ of rosuvastatin per day. Subsequently, each patient underwent a series of follow-up CTAs. All cases of ICAS took antiplatelet agent (aspirin or clopidogrel) for prevention of infarction.

\section{Clinical information}

A history of diabetes, hypertension, ischemic heart disease, smoking, dyslipidemia, and family history of cerebrovascular events was recorded. Laboratory tests were performed to assess the levels of total cholesterol, low-density lipoprotein (LDL), high-density lipoprotein (HDL), and triglycerides. All the patients received optimal medical management with aggressive control of the risk factors, including appropriate use of antiplatelet, antihypertensive, and antidiabetic drugs.

\section{Evaluation of stenosis}

The degree of stenosis was calculated using the method of the Warfarin-Aspirin Symptomatic Intracranial Disease Study:

percent stenosis $=[(1-($ Dstenosis $/$ Dnormal $)) \times 100.21)$

The regression was determined by two experienced neurovascular surgeons based on the difference between the initial and final follow-up stenosis measurements. Stenosis was measured on MIP images 
of CTA. The stenosis percentage was obtained using the length of the most severe stenosis as Dstenosis and the normal length on the proximal portion of stenosis as Dnormal.

\section{Statistics}

The Fisher's exact test or the Chi-squaretest were used to compare associations between the categorical variables. The lipid profile was analyzed with median cutoffs. The Student's t-test was used to compare continuous variables between the two groups. Multivariate analysis using binary logistic analysis included variables with p-values of 0.05 or less in the univariate analysis. The statistical analyses were performed with the IBM Social Sciences Statistical Package 17.0 software (SPSS Inc., Chicago, IL, USA). The level of statistical significance was set at $\mathrm{p}<0.05$.

\section{RESULTS}

\section{Cases}

Out of the 116,251 patients who visited the department of Neurosurgery at Kwangju Christian Hospital from August 2009 to December 2017, 6991 patients were examined with CTA. A total of 74 asymptomatic patients with hyperlipidemia were examined with CTA before the administration of $20 \mathrm{mg}$ rosuvastatin per day. Finally, 23 patients who did not undergo CTA during the follow-up examination were excluded and 48 patients with asymptomatic ICAS were included in the study.

Patients with an initial stenosis percentage of more than $30 \%$ were considered to be affected with ICAS. The regressed group included 30 patients with a value of stenosis difference higher than $15 \%$, the stationary group included 12 patients with a stenosis-dif-

Table 1. Characteristics of the two groups

\begin{tabular}{|c|c|c|c|c|}
\hline Group & & $\begin{array}{l}\text { Stationary/Progressed group } \\
\qquad(\mathrm{n}=18)\end{array}$ & $\begin{array}{l}\text { Regressed group } \\
\qquad(\mathrm{n}=30)\end{array}$ & $P$ value \\
\hline Age & Mean (SD) & $65.28(13.25)$ & $60.2(11.25)$ & 0.164 \\
\hline Sex (M:F, \%) & & $11: 7$ (61.1:38.9) & $16: 14$ (53.3:46.7) & 0.608 \\
\hline \multirow{3}{*}{ Medication (n, \%) } & Clopidogrel & $12(66.7)$ & 25 (83.3) & 0.191 \\
\hline & Hypertension & 11 (61.1) & $21(70)$ & 0.527 \\
\hline & Diabetes & $4(22.2)$ & 4 (13.3) & 0.424 \\
\hline Smoking (n, \%) & & $3(16.7)$ & $5(16.7)$ & 0.662 \\
\hline Family history of CVA (n, \%) & & $1(5.6)$ & 0 & 0.192 \\
\hline \multirow{9}{*}{ Location (n, \%) } & M1, Rt & $10(55.6)$ & 17 (56.7) & 0.942 \\
\hline & M1, Lt & $4(22.2)$ & 5 (16.7) & 0.642 \\
\hline & $\mathrm{M} 2$, Rt & $0(0.0)$ & 1 (3.3) & 0.445 \\
\hline & M2. Lt & $0(0.0)$ & 1 (3.3) & 0.445 \\
\hline & P1, Rt & $0(0.0)$ & $1(3.3)$ & 0.445 \\
\hline & P1, Lt & $1(5.6)$ & 1 (3.3) & 0.716 \\
\hline & P2, Rt & $1(5.6)$ & $0(0.0)$ & 0.200 \\
\hline & P2, Lt & $0(0.0)$ & $2(6.6)$ & 0.273 \\
\hline & $\mathrm{A} 2, \mathrm{Rt}$ & $2(11.1)$ & 1 (3.3) & 0.291 \\
\hline
\end{tabular}

SD standard deviation, CVA cerebrovascular accident, ${ }^{*} p<0.05$

Table 2. Stenosis changes and ischemic events in the two groups

\begin{tabular}{|c|c|c|c|c|}
\hline Group & & $\begin{array}{l}\text { Stationary/Progressed group } \\
\qquad(\mathrm{n}=18)\end{array}$ & $\begin{array}{l}\text { Regressed group } \\
\qquad(\mathrm{n}=30)\end{array}$ & $P$ value \\
\hline \multirow{3}{*}{ Stenosis, \%, mean (SD) } & Initial stenosis & 43.36 (15.39) & $53.42(16.58)$ & 0.440 \\
\hline & Last stenosis & 43.35 (14.57) & $24.33(16.17)$ & 0.264 \\
\hline & $\Delta$ stenosis & 0.01 (5.09) & $29.08(14.19)$ & $<0.001$ * \\
\hline Follow up duration, months, mean (SD) & & 24.11 (19.39) & $29.76(17.36)$ & 0.677 \\
\hline Ischemic event during follow up (N, \%) & & $2(6.6)$ & $0(0)$ & 0.062 \\
\hline
\end{tabular}

SD standard deviation, ${ }^{*} p<0.05$ 
ference value within 10\%, and the progressed group included 6 patients with a stenosis-difference value below zero. The stationary and progressed groups included fewer patients than the regressed group and the variance of the stenosis-difference values between the stationary and progressed groups was narrow. The difference between the groups was assessed using the value of the stenosis difference, which was calculated by subtracting the final stenosis value from the initial stenosis value. Due to the narrow stenosis difference between the groups, a three-group analysis was deemed in appropriate, therefore, the stationary group and the progressed group were combined into the stationary/progressed group for the ease of statistical analysis.

\section{Baseline characteristics}

The demographic data of the patients are summarized in Table 1. The mean age was $65.28 \pm 13.25$ years in the stationary/progressed group and $60.2 \pm 11.25$ years in the regressed group. There were 11 men $(61.1 \%)$ in the stationary/progressed group and 16 men $(53.3 \%)$ in the regressed group. The patients were being treated for underlying diseases such as hypertension, diabetes mellitus, and heart disease. To prevent cerebral infarction, 11 patients $(22.9 \%)$ were taking aspirin and 37 patients (77.1\%) were taking clopidogrel according to the patient's drug resistance test results. Cilostazol was not administered on any patient. The administration of antiplatelet and antihypertensive drugs, which are considered to influence stenosis, were controlled. The most common site of ICAS was M1 (36 patients, $72.9 \%$ ). The other sites were P2 (4, 8.4\%), P1 (3, 6.3\%), A2 (3, 6.3\%), M2 (2, $4.2 \%)$, and $\mathrm{A} 1(1,2.1 \%)$. There were more right-side M1 lesions $(27,56.3 \%)$ than left-side M1 lesions (9, $18.8 \%)$.

\section{Stenosis change and ischemic events}

The initial stenosis was $43.36 \pm 15.39 \%$ in the stationary/progressed group and $53.42 \pm 16.58 \%$ in the regressed group. The final follow-up stenosis was $45.60 \pm 10.05 \%$ in the stationary/progressed group and $24.33 \pm 16.17 \%$ in the regressed group (Table 2). The differences between the groups were not statistically significant; however, the difference between the initial and final follow-up stenosis value was statistically significant between the two groups $(\mathrm{p}<0.001$, Table 2). The representative images of M1 stenosis of a 60-year-old male patient from the regressed group who was administered $20 \mathrm{mg} /$ day of rosuvastatin for 46 months are shown in Fig. 1 . In the stationary/progressed group, ischemic stroke or TIA in the territory of asymptomatic ICAS developed in 2 patients during the follow-up period. One patient, a 75-year-old woman with, hypertension and right M1 stenosis, developed cerebral infarction in the right parietal area that was, detected at 6 months of follow-up. Another patient, a 74-year-old woman with, hypertension and left P1 stenosis, developed a cerebral infarction in the left thalamus that was, detected at 42 months of follow-up. However, in the regressed group, no ischemic event was observed during the follow-up period.

\section{Dyslipidemia analyses}

All the described differences between the initial and final measurements were calculated by subtracting the final value from the initial value. Among the variables of dyslipidemia, the differences in total cholesterol $(p=0.031)$ and LDL $(p=0.031)$ between the initial and final measurements were higher in the regressed group than in the stationary/progressed group in the univariate analysis (Table 3). The multivariate analysis of significant variables including $\Delta$ total cholesterol and $\Delta \mathrm{LDL}$, which showed statistical significance, revealed higher $\Delta$ LDL $(\mathrm{p}=0.035)$ in the regressed group. The odds ratio was 3.9 , which signified that patients with an increased difference between the initial and final LDL values were 3.9 times more likely to be in the regressed group (Table 4).

\section{DISCUSSION}

We conducted this study to evaluate whether 

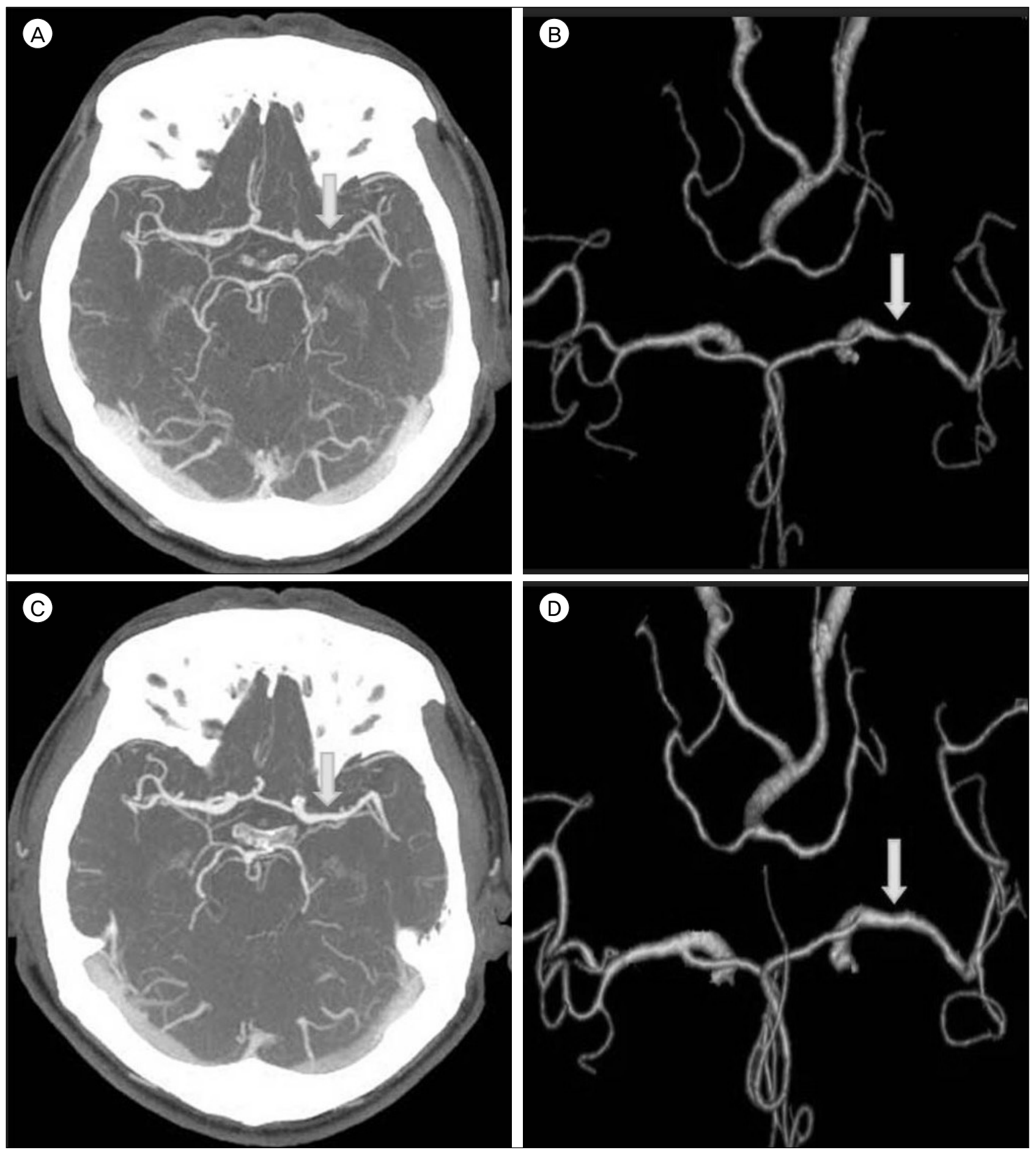

Fig. 1. (A, B) CT scan and 3-dimensional (3D) reconstructed computed tomography angiography (CTA) images reveal severe stenosis on the M1. (C, D) After 46-month administration of rosuvastatin, CT scan and 3D-reconstructed CTA images show a regressed stenotic lesion.

asymptomatic ICAS regressed or remained unchanged/ progressed after the administration of rosuvastatin while considering the associated factors of ICAS.
Our major finding was that rosuvastatin had better lipid-lowering effects in terms of total cholesterol and particularly LDL in patients with regressed ICAS. 
Moreover, 2 patients of the stationary/progressed group developed ischemic events in the stenosed vascular territory, while no such events were observed in the regressed group.

Antiplatelet agents aspirin and clopidogrel, which are not known to not have any particular effect on vasodilation, were used for the patients in this study. Other antiplatelet agents, such as cilostazol, which stabilize endothelial cells and inhibit proliferation of vascular smooth-muscle cells causing vasodilation, were not used. ${ }^{24)}$ Therefore, the effects of other antiplatelet drugs on the vascular-structure modification may be excluded.

Statins are known to have stabilizing effects on vascular endothelial cells and can be used to slow the progression of and even regress atherosclerosis.' ${ }^{7}$ The beneficial effect of statins on the regression of carotid intima media thickness has been widely demonstrated. ${ }^{39) 12)}$ It was reported that statin treatment in patients with carotid stenosis decreased the neutrophil activation and related vulnerability by reducing the systemic activation of the receptor activator of the NF-KB ligand-osteoprotegerin system. ${ }^{17)}$

Statins can be administered to patients with hyperlipidemia starting at dosages of 5-10 mg/day. The adverse effects of high doses of statins include liver toxicity, rhabdomyolysis, and impaired glucose tolerance that leads to diabetes. ${ }^{10)}$ Thus, the administration of statins should be done cautiously. In this study, 20 $\mathrm{mg} /$ day of rosuvastatin was administered and no adverse effects were observed, which meant that it could be used to treat asymptomatic ICAS.

Table 3. Dyslipidemia data of the two groups

\begin{tabular}{|c|c|c|c|c|c|}
\hline Group & & & $\begin{array}{c}\text { Stationary/Progressed } \\
\text { group }(n=18)\end{array}$ & $\begin{array}{l}\text { Regressed group } \\
(n=30)\end{array}$ & $P$ value \\
\hline \multirow[t]{12}{*}{ Dyslipidemia, mg/dl, n, \% } & Initial total cholesterol & $\begin{array}{l}<172.5 \\
\geq 172.5\end{array}$ & $\begin{array}{ll}9 & (50.0) \\
9 & (50.0)\end{array}$ & $\begin{array}{ll}14 & (46.7) \\
16 & (53.3)\end{array}$ & 0.823 \\
\hline & Initial triglyceride & $\begin{array}{l}<116.5 \\
\geq 116.5\end{array}$ & $\begin{array}{r}10 \\
8(55.6) \\
8(44.4)\end{array}$ & $\begin{array}{ll}15 & (50.0) \\
15 & (50.0) \\
\end{array}$ & 0.709 \\
\hline & Initial HDL & $\begin{array}{l}<42 \\
\geq 42\end{array}$ & $\begin{array}{ll}9 & (50.0) \\
9 & (50.0)\end{array}$ & $\begin{array}{ll}14 & (46.7) \\
16 & (53.3) \\
\end{array}$ & 0.823 \\
\hline & Initial LDL & $\begin{array}{l}<93.5 \\
\geq 93.5\end{array}$ & $\begin{array}{rr}11 & (61.1) \\
7 & (38.8)\end{array}$ & $\begin{array}{ll}12 & (40.0) \\
18 & (60.0)\end{array}$ & 0.156 \\
\hline & Last total cholesterol & $\begin{array}{l}<141.5 \\
\geq 141.5\end{array}$ & $\begin{array}{rr}6 & (33.3) \\
12 & (66.7) \\
\end{array}$ & $\begin{array}{ll}17 & (56.7) \\
13 & (43.3)\end{array}$ & 0.117 \\
\hline & Last triglyceride & $\begin{array}{l}<96.5 \\
\geq 96.5\end{array}$ & $\begin{aligned} 11 & (61.1) \\
7 & (38.8)\end{aligned}$ & $\begin{array}{ll}13 & (43.3) \\
17 & (56.7)\end{array}$ & 0.233 \\
\hline & Last HDL & $\begin{array}{l}<41 \\
\geq 41\end{array}$ & $\begin{array}{ll}9 & (50.0) \\
9 & (50.0)\end{array}$ & $\begin{array}{ll}16 & (53.3) \\
14 & (46.7)\end{array}$ & 0.823 \\
\hline & Last LDL & $\begin{array}{l}<70.5 \\
\geq 70.5\end{array}$ & $\begin{array}{ll}9 & (50.0) \\
9 & (50.0)\end{array}$ & $\begin{array}{ll}14 & (46.7) \\
16 & (53.3)\end{array}$ & 0.823 \\
\hline & $\Delta$ total cholesterol & $\begin{array}{l}<13 \\
\geq 13\end{array}$ & $\begin{array}{r}13(72.2) \\
5(27.8) \\
\end{array}$ & $\begin{array}{ll}12 & (40.0) \\
18 & (60.0) \\
\end{array}$ & $0.031^{*}$ \\
\hline & $\Delta$ triglyceride & $\begin{array}{l}<5 \\
\geq 5\end{array}$ & $\begin{array}{rr}10 & (55.6) \\
8 & (44.4)\end{array}$ & $\begin{array}{ll}14 & (46.7) \\
16 & (53.3)\end{array}$ & 0.551 \\
\hline & $\Delta \mathrm{HDL}$ & $\begin{array}{l}<-1.5 \\
\geq-1.5\end{array}$ & $\begin{array}{r}6(33.3) \\
12(66.7)\end{array}$ & $\begin{array}{ll}17 & (56.7) \\
13 & (43.3)\end{array}$ & 0.117 \\
\hline & $\Delta \mathrm{LDL}$ & $\begin{array}{l}<6.5 \\
\geq 6.5\end{array}$ & $\begin{array}{r}13(72.2) \\
5(27.8)\end{array}$ & $\begin{array}{ll}12 & (40.0) \\
18 & (60.0)\end{array}$ & $0.031^{*}$ \\
\hline
\end{tabular}

SD standard deviation, LDL low density lipoprotein, HDL high density lipoprotein, ${ }^{*} \mathrm{p}<0.05$

Table 4. Multivariable analysis of the variables that were found statistically significant in the regressed asymptomatic ICAS group in the univariate analysis

\begin{tabular}{lll}
\hline Variable & Odds Ratio (95\% Confidence Interval) & P-value \\
\hline$\Delta$ total cholesterol & $2.552(0.621-10.498)$ & 0.194 \\
$\Delta$ LDL & $3.900(1.102-13.802)$ & $0.035^{*}$ \\
\hline${ }^{*} \mathrm{p}<0.05$ & &
\end{tabular}


Studies on the effect of rosuvastatin on the coronary and carotid arteries have made quantitative assessments of atherosclerosis using angiography or ultrasonography. ${ }^{725)}$ The ORION study, which examined the effects of rosuvastatin administration on carotid artery stenosis, showed that the rosuvastatin-administration groups (5mg/day vs. $40-80 \mathrm{mg} /$ day) showed no difference on the carotid-plaque volume. However, patients who had a lipid-rich necrotic core in the carotid plaque at the baseline showed decreased carotid-plaque volume (41\%) after administration of rosuvastatin. ${ }^{25)}$

CTA is a widely used imaging modality, employed to visualize the arterial lumen. It is a minimally-invasive technique that uses radiation and intravenous radiocontrast material. CTA provides similar or higher accuracy for the detection of ICAS as compared to magnetic resonance angiography, except in the region of the skull base, and reportedly has higher acquisition speed and lower distortion due to motion artifacts. ${ }^{222}$ Since CTA cannot depict the lipid component in the stenotic lesions of the intracranial arteries, it was difficult for us to determine the association between the laboratory results and the imaging data of the quantitative lipid-content change in the stenotic lesions in this study.

The general risk factors associated with asymptomatic ICAS are hypertension, diabetes, dyslipidemia, metabolic syndrome, age, male sex, and ethnicity (Asians and Africans) ${ }^{1}$. Risk factors associated with the severity of ICAS include diabetes, smoking, metabolic syndrome, and dyslipidemia. ${ }^{1)}$ However, two distinctive characteristics of ICAS are: atherosclerosis produced by cholesterol deposition and inflammation and sclerosis secondary to endothelial dysfunction, both of which cause arterial stiffness. ${ }^{11)}$ Therefore, the risk factors of intracranial atheromatous plaque and plaque-negative stenosis are different. ${ }^{20)}$

A study on symptomatic ICAS patients who had a history of ischemic events found that sex is a major predictor of ICAS regression. ${ }^{23)}$ Another study re- ported that asymptomatic ICAS showed a lower rate of progression than symptomatic ICAS. ${ }^{13)}$ This study also suggested that a low fasting glucose level and the use of angiotensin receptor blockers were associated with a favorable course of asymptomatic ICAS. In this study, we found that the differences between the initial and final values of total cholesterol and LDL were associated with ICAS regression. This finding indicates that the patients in whom the medication shows favorable lipid-lowering effects may have a better modulation capability of the ICAS lesion structure by modulating the atherosclerotic plaque in the lipid-laden area of the vessel.

This study has several limitations. The study included a small number of the patients from a single center. Although significant stenosis is defined as more than $50 \%$ arterial blockage, in this study, the sample was based on $30 \%$ blockage because of the small sample size. Moreover, the association between other clinical information of the patients and features of the stenotic lesion, especially the lesion's lipid component, was not investigated. Although CTA is an appropriate imaging modality to detect ICAS and is less affected by motion artifacts, the degree of stenosis and the quantification of the intracranial vascular lipid components, especially in small vessels, are difficult to investigate using this method. Further studies with larger sample sizes on a multicenter scale using a modality capable of ICAS-component quantification are required.

\section{CONCLUSION}

We evaluated the factors associated with ICAS regression after the administration of high-dose rosuvastatin. The differences between the initial and final measured values of total cholesterol and LDL were statistically significantly associated with the regression of ICAS. Our findings support the notion that rosuvastatin had better lipid-lowering effects in patients whose stenotic vessels were regressed. 


\section{Disclosure}

The authors declare no conflicts of interest.

\section{REFERENCES}

1. Bang OY. Intracranial atherosclerosis: current understanding and perspectives. Journal of stroke. 2014;16(1):27.

2. Bash S, Villablanca JP, Jahan R, Duckwiler G, Tillis M, Kidwell $\mathrm{C}$, et al. Intracranial vascular stenosis and occlusive disease: evaluation with CT angiography, MR angiography, and digital subtraction angiography. American Journal of Neuroradiology. 2005;26(5):1012-21.

3. Bedi US, Singh M, Singh PP, Bhuriya R, Bahekar A, Molnar J, et al. Effects of statins on progression of carotid atherosclerosis as measured by carotid intimal-medial thickness: a meta-analysis of randomized controlled trials. Journal of cardiovascular pharmacology and therapeutics. 2010;15(3):268-73.

4. Caplan LR. Intracranial branch atheromatous disease A neglected, understudied, and underused concept. Neurology. 1989;39(9):1246-.

5. Carvalho M, Oliveira A, Azevedo E, Bastos-Leite AJ. Intracranial arterial stenosis. Journal of Stroke and Cerebrovascular Diseases. 2014;23(4):599-609.

6. Chimowitz MI, Lynn MJ, Derdeyn CP, Turan TN, Fiorella D, Lane BF, et al. Stenting versus aggressive medical therapy for intracranial arterial stenosis. New England Journal of Medicine. 2011;365(11):993-1003.

7. Crouse JR, Raichlen JS, Riley WA, Evans GW, Palmer MK, O'Leary DH, et al. Effect of rosuvastatin on progression of carotid intima-media thickness in low-risk individuals with subclinical atherosclerosis: the METEOR Trial. Jama. 2007;297(12):1344-53.

8. Derdeyn CP, Chimowitz MI, Lynn MJ, Fiorella D, Turan TN, Janis LS, et al. Aggressive medical treatment with or without stenting in high-risk patients with intracranial artery stenosis (SAMMPRIS): the final results of a randomised trial. The Lancet. 2014;383(9914):333-41.

9. Espeland MA, O'Leary DH, Terry JG, Morgan T, Evans G, Mudra H. Carotid intimal-media thickness as a surrogate for cardiovascular disease events in trials of HMG-CoA reductase inhibitors. Current controlled trials in cardiovascular medicine. 2005;6(1):3.

10. Golomb BA, Evans MA. Statin adverse effects. American Journal of Cardiovascular Drugs. 2008;8(6):373-418.

11. Gomez CR, Qureshi AI. Medical treatment of patients with intracranial atherosclerotic disease. Journal of Neuroimaging. 2009;19(S1):25S-9S.

12. Huang Y, Li W, Dong L, Li R, Wu Y. Effect of statin therapy on the progression of common carotid artery intima-media thickness: an updated systematic review and meta-analysis of randomized controlled trials. Journal of atherosclerosis and thrombosis. 2013;20(1):108-21.

13. Kim BJ, Hong K-S, Cho Y-J, Lee J-H, Koo J-s, Park J-M, et al. Predictors of symptomatic and asymptomatic intracranial atherosclerosis: what is different and why? Journal of atherosclerosis and thrombosis. 2014;21(6):
605-17.

14. Kim JS, Caplan LR, Wong KL. Intracranial atherosclerosis: John Wiley \& Sons; 2009.

15. Kremer C, Schaettin T, Georgiadis D, Baumgartner R. Prognosis of asymptomatic stenosis of the middle cerebral artery. Journal of Neurology, Neurosurgery \& Psychiatry. 2004;75(9):1300-3.

16. Lau AY, Wong EH, Wong A, Mok VC, Leung TW, Wong K-sL. Significance of good collateral compensation in symptomatic intracranial atherosclerosis. Cerebrovascular diseases. 2012;33(6):517-24.

17. Lenglet S, Quercioli A, Fabre M, Galan K, Pelli G, Nencioni A, et al. Statin treatment is associated with reduction in serum levels of receptor activator of NF- $\mathrm{kB}$ ligand and neutrophil activation in patients with severe carotid stenosis. Mediators of inflammation. 2014;2014.

18. Liebeskind DS, Cotsonis GA, Saver JL, Lynn MJ, Turan $\mathrm{TN}$, Cloft HJ, et al. Collaterals dramatically alter stroke risk in intracranial atherosclerosis. Annals of neurology. 2011;69(6):963-74.

19. Matsui R, Nakagawa T, Takayoshi H, Onoda K, Oguro $\mathrm{H}$, Nagai A, et al. A prospective study of asymptomatic intracranial atherosclerotic stenosis in neurologically normal volunteers in a Japanese cohort. Frontiers in neurology. 2016;7:39.

20. Mazighi M, Labreuche J, Gongora-Rivera F, Duyckaerts C, Hauw J-J, Amarenco P. Autopsy prevalence of intracranial atherosclerosis in patients with fatal stroke. Stroke. 2008;39(4):1142-7.

21. Samuels OB, Joseph GJ, Lynn MJ, Smith HA, Chimowitz MI. A standardized method for measuring intracranial arterial stenosis. American journal of neuroradiology. 2000;21(4):643-6.

22. Skutta B, Fürst G, Eilers J, Ferbert A, Kuhn F-P. Intracranial stenoocclusive disease: double-detector helical CT angiography versus digital subtraction angiography. American Journal of Neuroradiology. 1999;20(5):791-9.

23. Tan T-Y, Kuo Y-L, Lin W-C, Chen T-Y. Effect of lipid-lowering therapy on the progression of intracranial arterial stenosis. Journal of neurology. 2009;256(2):187-93.

24. Tanaka $\mathrm{T}$, Ishikawa $\mathrm{T}$, Hagiwara $\mathrm{M}$, Onoda $\mathrm{K}$, Itoh $\mathrm{H}$, Hidaka H. Effects of cilostazol, a selective cAMP phosphodiesterase inhibitor on the contraction of vascular smooth muscle. Pharmacology. 1988;36(5):313-20.

25. Underhill HR, Yuan C, Zhao X-Q, Kraiss LW, Parker $\mathrm{DL}$, Saam T, et al. Effect of rosuvastatin therapy on carotid plaque morphology and composition in moderately hypercholesterolemic patients: a high-resolution magnetic resonance imaging trial. American heart journal. 2008; 155(3):584. e1-. e8.

26. Wong KS, Li H. Long-term mortality and recurrent stroke risk among Chinese stroke patients with predominant intracranial atherosclerosis. Stroke. 2003;34(10) 2361-6.

27. Wong MC, Wang HH. Rapid emergence of atherosclerosis in Asia: a systematic review of coronary atherosclerotic heart disease epidemiology and implications for prevention and control strategies. Current opinion in lipidology. 2015;26(4):257-69. 